\title{
Comment on "Replacing the NCCN's Blocks with Wheels: How Should Consideration of Societal Spending be Incorporated into Oncology Practice?"
}

\author{
Wui-Jin Koh ${ }^{1} \cdot$ Robert W. Carlson ${ }^{1,2}$ (D)
}

Published online: 26 June 2020

(c) The Author(s) 2020

\section{To the Editor,}

We write to clarify the function of the NCCN Evidence Blocks ${ }^{\mathrm{TM}}$, a visual tool that enables oncologists to see, at a glance, representation of five key measures of a therapy or treatment regimen in the NCCN Clinical Practice Guidelines in Oncology (NCCN Guidelines ${ }^{\circledR}$ ) [1]. These five measures include efficacy, safety, quality and quantity of evidence, consistency of evidence, and affordability. The final category of affordability was added in 2015 to facilitate shared decision making between provider and patient based on discussion of the patient's values and goals. By adding affordability to NCCN's existing criteria for evaluating treatment options, patients are empowered to identify, alongside their physician, optimal treatment based on clinical and economic considerations that are of most value to them.

In the commentary published online in PharmacoEconomics April 24, 2020 by Tran and Prasad [2], the authors suggest that in developing the affordability measure of the NCCN Evidence Blocks ${ }^{\mathrm{TM}}$ doctors are considering societal costs when deciding therapies. This is most definitely not something that either the NCCN panelists who develop the guidelines or the oncologists who use them are expected to do. Nor are the NCCN Evidence Blocks ${ }^{\mathrm{TM}}$ intended to

This comment refers to the article available online at https://doi. org/10.1007/s40273-020-00920-8 and https://doi.org/10.1007/ s40273-020-00939-x.

Robert W. Carlson

carlson@nccn.org

Wui-Jin Koh

koh@nccn.org

1 National Comprehensive Cancer Network, 3025 Chemical Road, Suite 100, Plymouth Meeting, PA 19462, USA

2 Department of Medicine, Division of Medical Oncology, Stanford University Medical Center, Stanford, CA 94305, USA reduce healthcare spending, as much as we wish to see it. NCCN's mission is to improve and facilitate quality, effective, efficient, and accessible cancer care so patients can live better lives.

By design, the affordability measurement is not based directly on drug or treatment prices. Rather, it represents an estimate of overall relative total cost of a therapy, including but not limited to acquisition, administration, site of care, infusions, laboratory monitoring, anti-emetics and growth factors, and toxicity management. No precise cost is provided, as costs, including cost to the patient, vary greatly depending on insurance contract, deductible, location of care, experienced toxicity, and multiple other factors that make absolute calculations that are universally applicable to individual patients impossible. Rather, the affordability estimate is envisioned as a conversation starter in shared decision-making regarding treatment options.

Some patients want an emerging therapy even with limited data; others are more concerned about the expected side effects of the treatment. Still others are extremely sensitive to cost. By considering the attributes of the range of possible therapies, the healthcare provider and the patient can discuss and balance the benefits and drawbacks of each option and come to a decision most acceptable to the individual.

In generating NCCN Clinical Practice Guidelines in Oncology including the Evidence Blocks, NCCN is doing what NCCN has done for 25 years-offering transparent, evidence-based and continually updated treatment guidelines that enable high-quality decision making and access to care to remain with informed patients and their providers.

\section{Compliance with Ethical Standards}

Conflict of interest Dr. Koh is employed by the National Comprehensive Cancer Network as Chief Medical Officer. Dr. Carlson is employed by the National Comprehensive Cancer Network as Chief Executive 
Officer. Display patents for Evidence Blocks have been awarded in Dr. Carlson's name on behalf of NCCN.

Open Access This article is licensed under a Creative Commons Attribution-NonCommercial 4.0 International License, which permits any non-commercial use, sharing, adaptation, distribution and reproduction in any medium or format, as long as you give appropriate credit to the original author(s) and the source, provide a link to the Creative Commons licence, and indicate if changes were made. The images or other third party material in this article are included in the article's Creative Commons licence, unless indicated otherwise in a credit line to the material. If material is not included in the article's Creative Commons licence and your intended use is not permitted by statutory regulation or exceeds the permitted use, you will need to obtain permission directly from the copyright holder. To view a copy of this licence, visit http://creativecommons.org/licenses/by-nc/4.0/.

\section{References}

1. Carlson RW, Jonasch E. NCCN evidence blocks. J Natl Compr Canc Netw. 2016;14(5S):617-9. https://doi.org/10.6004/jncen 2016.0177.

2. Tran AA, Prasad V. Replacing the NCCN's blocks with wheels: how should consideration of societal spending be incorporated into oncology practice? Pharmacoeconomics. 2020. https://doi. org/10.1007/s40273-020-00920-8. 